\title{
A CLINICAL STUDY OF MULTIPLE CRANIAL NEUROPATHIES (MCN)
}

\author{
G. Sree Ranga Lakshmi ${ }^{1}$, R. Ramesh ${ }^{2}$, K. Suma ${ }^{3}$, S. Narmada 4 , P. Vijaya laxmi ${ }^{5}$, K. Kiran ${ }^{6}$, M. Deepti ${ }^{7}$
}

${ }^{1}$ Associate Professor, Department of Neurology, Osmania Hospital, Hyderabad, Telangana.

${ }^{2}$ Assistant Professor, Department of Neurology, Osmania Hospital, Hyderabad, Telangana.

${ }_{3}^{3}$ Senior Resident, Department of Neurology, Osmania Hospital, Hyderabad, Telangana.

${ }^{4}$ Postgraduate, Department of Neurology, Osmania Hospital, Hyderabad, Telangana.

5 Postgraduate, Department of Neurology, Osmania Hospital, Hyderabad, Telangana.

${ }^{6}$ Postgraduate, Department of Neurology, Osmania Hospital, Hyderabad, Telangana.

7 Postgraduate, Department of Neurology, Osmania Hospital, Hyderabad, Telangana.

\section{ABSTRACT}

\section{BACKGROUND}

Cranial neuropathies are frequently seen by neurologist. The causes are many and evaluation presents a unique challenge for the diagnostician. The differential diagnosis is broad and includes infections, inflammatory conditions, cavernous sinus lesions, and many life-threatening processes like neoplastic meningitis A knowledge of the anatomy of the cranial nerves and their involvement in pathologic processes is therefore one of the corner stones of neurologic diagnosis. Just as with any other neurologic presentation, the first step in the evaluation requires correct localization. Processes affecting multiple cranial nerves may involve intramedullary structures of the brainstem as well as their extramedullary course. The majority of the literature regarding aetiologies of multiple cranial neuropathies consists of case reports or small case series with very few reported large series. The largest reported series to date of multiple cranial neuropathies was that of Keane.

\section{KEYWORDS}

Multiple Cranial Neuropathies, Diphtheria, Infections and Meningitis, Skull Base Tumours, Carcinomatous Meningitis, Cavernous Sinus Syndrome.

HOW TO CITE THIS ARTICLE: Lakshmi GSR, Ramesh R, Suma K, et al. A clinical study of multiple cranial neuropathies (mcn). J. Evolution Med. Dent. Sci. 2016;5(54):3653-3656, DOI: 10.14260/jemds/2016/841

\section{INTRODUCTION}

The 12 pairs of cranial nerves innervate most structures of the head and neck, which traverse the meninges, subarachnoid space, bony structures of the cranium, and soft tissues. Disruption of these nerves at any site along their course can manifest by cranial nerve dysfunction.(1) Evaluation of the patient with multiple cranial neuropathies presents a unique challenge for the diagnostician. The differential diagnosis is broad and includes many life-threatening processes. These disease processes may involve homologous nerves on the two sides (eg, Bilateral facial palsy) or different nerves on the same or contralateral side. The progression of cranial nerve dysfunction may follow some anatomical pattern or appear randomly. Multiple cranial nerves may be affected from the beginning or the process may begin with one nerve with subsequent involvement of others. The presence or absence of pain may also provide a clue to the diagnosis. The differential diagnosis associated with multiple cranial nerve palsies is extensive and one must develop a systematic way to approach these patients.

The majority of the literature regarding aetiologies of multiple cranial neuropathies consists of case reports or small case series with very few reported large series. The largest reported series to date of multiple cranial neuropathies was that of Keane.(2)

Financial or Other, Competing Interest: None.

Submission 16-06-2016, Peer Review 29-06-2016,

Acceptance 02-07-2016, Published 07-07-2016.

Corresponding Author:

Dr. G. Sree Ranga Lakshmi,

Associate Professor,

Department of Neurology,

Osmania General Hospital,

Hyderabad, Telangana.

E-mail: rangalakshmi2000@gmail.com

DOI: $10.14260 /$ jemds $/ 2016 / 841$

\section{AIM OF THE STUDY}

To evaluate the causes of multiple cranial neuropathies in patients attending Osmania General Hospital.

\section{METHODS}

This was a cross-sectional study conducted in Osmania General Hospital from September 2012 to December 2014.

\section{Inclusion Criteria}

Patients with simultaneous or serial involvement of two or more different cranial nerves were included in the study.

\section{Exclusion Criteria}

Patients with myasthenia gravis and motor neuron disease were excluded.

Detailed history was taken with special emphasis on mode of onset of illness, duration, progression, relevant past medical and surgical history. Any constitutional symptoms were noted. Complete systemic and neurological examination was done.

\section{Laboratory Investigations}

Basic tests like CBP, ESR, blood urea, serum creatinine, serum electrolytes were done in all patients. CSF analysis was done to the selected patients for cell count, biochemical analysis for sugars, proteins, ADA levels, Gram, AFB, and fungal staining as well as culture and sensitivity. CSF cytology for malignant cells has been done when it is clinically required. Brain imaging (CT/MRI) was done in patients on clinical basis. Contrast imaging was done if clinically indicated. MRA or CT angiography, MRS, MRI spine with or without contrast, USG abdomen, Chest X-Ray, X-Ray, or CT paranasal sinuses were done in some patients as clinically indicated. Electrophysiological studies, biopsies, throat swab, CSF 
oligoclonal bands, SSS (Split Skin Smear) tests, blood culture were done in some cases as clinically indicated.

\section{RESULTS}

Total 200 patients with multiple cranial neuropathy met the inclusion criteria, out of which 116 (58\%) were males and 84 $(42 \%)$ were females.

\begin{tabular}{|c|c|c|c|}
\hline Age Group in Years & Male & Female & Total \\
\hline $0-10$ & 22 & 14 & 36 \\
\hline $11-20$ & 23 & 19 & 42 \\
\hline $21-30$ & 18 & 20 & 38 \\
\hline $31-40$ & 23 & 13 & 36 \\
\hline $41-50$ & 12 & 6 & 18 \\
\hline $51-60$ & 9 & 6 & 15 \\
\hline $61-70$ & 5 & 6 & 11 \\
\hline $71-80$ & 4 & & 4 \\
\hline \multicolumn{3}{|c|}{ Table 1: Age Group in Years } \\
\hline
\end{tabular}

Aetiology: The various aetiologies are depicted in the table 2 .

\begin{tabular}{|c|c|}
\hline Aetiology & No. of Patients \\
\hline Post-Diphtheritic Paralysis & 45 \\
\hline GB Syndrome & 30 \\
\hline Other Infections & 30 \\
\hline Tumours & 28 \\
\hline Vascular Disease & 20 \\
\hline MFS & 2 \\
\hline MS and ADEM & 14 \\
\hline & \\
\hline Cavernous Sinus Syndrome & 5 \\
\hline ACM I & 3 \\
\hline CNS Complications of Systemic Cancer & 6 \\
\hline Trauma & 5 \\
\hline CIDP & 3 \\
\hline Miscellaneous & 8 \\
\hline Unknown & 1 \\
\hline Table 2: Aetiologies of Multiple Cranial Neuropathies \\
\hline
\end{tabular}

Post-diphtheritic polyneuropathy was responsible for 45 (22.5\%) of the 200 cases. Out of 45 cases, 23 (51\%) were male, and $22(49 \%)$ were female with mean age of 15 years ranging from 7 to 35 years. 41 (91\%) patients developed bulbar palsy and 9 of them also developed bilateral $7^{\text {th }}$ nerve palsy, 4 (9\%) cases presented with bulbar palsy and descending paralysis and 2 of them were associated with bilateral $7^{\text {th }}$ nerve palsy. While none of the cases developed respiratory paralysis, 5 (11\%) of them also developed myocarditis.

In $30(15 \%)$ patients, infections (Other than diphtheria) were responsible for cranial neuropathy. (Table 3). The patient with retroviral disease had involvement of fifth and sixth nerves on right side and third nerve on left side.

\begin{tabular}{|cl|c|}
\hline Type of Infection & \multicolumn{1}{c|}{$\begin{array}{c}\text { Number of } \\
\text { Patients }\end{array}$} \\
\hline 1. & Meningitis & 1 \\
& $\bullet \quad$ Bacterial & 18 \\
\hline 2. & Fungal-Mucormycosis & 3 \\
\hline 3. & Hanson' Disease & 4 \\
\hline 4. & Retroviral Infection & 1 \\
\hline 5. & CSOM with 6th and 7th Nerve & 3 \\
\hline \multicolumn{2}{|c|}{ Palsy Total } & $\mathbf{3 0}$ \\
\hline \multicolumn{2}{|c|}{ Table 3: Infectious Causes of MCN } \\
\hline \multicolumn{2}{|c|}{ (Excluding Diphtheria) } \\
\hline
\end{tabular}

In 27 patients (13.5\%), intracranial tumours were responsible for cranial neuropathies (Table 4).

\begin{tabular}{|c|c|}
\hline Tumours & Counts \\
\hline Meningiomas & 9 \\
\hline Schwannoma & 5 \\
\hline Chordoma & 2 \\
\hline Epidermoid Cyst & 4 \\
\hline Gliomas & 2 \\
\hline Craniopharyngioma & 1 \\
\hline Pituitary Adenoma & 3 \\
\hline Adenoid Cystic Carcinoma & 1 \\
\hline Table 4: Tumours That Produced $\mathbf{M C N}$ \\
\hline
\end{tabular}

MCN as a complication of systemic malignancies is seen in $6(3 \%)$ patients, all were male patients with a mean age of 28.5 years. All were due to Non-Hodgkin's lymphoma out of which 3 were due to neurolymphomatosis and 3 were due to leptomeningeal involvement.

Vascular lesions are responsible for cranial neuropathies in 20 patients $(10 \%)$. Eight patients had posterior cerebral artery infarcts, two patients had pontine bleed, one patient presented with saccular aneurysm of ICA, and one patient had cavernous sinus thrombosis. The remaining eight patients had ischemic cranial neuropathies in whom vascular risk factors like hypertension and diabetes were present. The MR Imaging of brain and CSF analysis were noncontributory in these eight patients. These were classified under non-localizing group.

Central demyelination was responsible for MCN in $14(7 \%)$ cases out of which 12 had ADEM and 2 were diagnosed with Multiple Sclerosis.

GB syndrome in 30 patients and Miller-Fisher syndrome in two patients were responsible for cranial neuropathy and in 3 patients chronic demyelinating inflammatory polyneuropathy was the cause.

Traumatic causes of neuropathy were seen in 5 (2.5\%) cases due to temporal and orbital bone fractures. Other miscellaneous aetiologies included $5(2.5 \%)$ cases of TolosaHunt syndrome, 3 cases due to syrinx with Chiari malformation, Wernicke's encephalopathy (2 patients), Ramsay Hunt syndrome with VIII and VII nerve palsy (1 patient), osteopetrosis (1 patient), fibrous dysplasia (1 patient), congenital cranial nerve palsy due to Moebius syndrome (1 patient), acute myelitis involving cervicomedullary junction ( 2 patients). One patient presented with left fifth and twelfth cranial neuropathy and we could not find the aetiology.

\begin{tabular}{|c|c|}
\hline Localisation & Counts \\
\hline Cavernous Sinus & 12 \\
\hline Cerebellopontine Angle & 15 \\
\hline Brain Stem & 28 \\
\hline Nerve & 86 \\
\hline Subarachnoid Space & 26 \\
\hline Clivus and Skull Base & 11 \\
\hline Vertebrae & 1 \\
\hline Unknown & 1 \\
\hline Cervicomedullary Junction & 5 \\
\hline Sellar Tumours & 4 \\
\hline Intra-orbital & 10 \\
\hline Non-Localizing (MFS included) & 1 \\
\hline Table 5: Localization of Lesion in the Nerves
\end{tabular}


The localisation was in the extra cranial course in 86 patients, post-diphtheritic palsy (In 45 patients) being the most frequent cause followed by GBS and MFS (32 patients). The next common localization was brainstem (28 Cases). The other sites were in subarachnoid space in 26 patients, cavernous sinus in 12 patients, cerebellopontine lesions in 15 patients, and skull base in 11 patients.

The combinations of cranial nerves involved are shown in Table 6.

\begin{tabular}{|c|c|}
\hline $\begin{array}{c}\text { Common Combinations of } \\
\text { Cranial Nerve Involved }\end{array}$ & Counts \\
\hline IX, X & 109 \\
\hline IX, X, VII & 57 \\
\hline III, IV, VI & 37 \\
\hline III, IV, VI & 21 \\
\hline VIII, VII & 18 \\
\hline VIII, V & 14 \\
\hline III, IV, VI, V & 7 \\
\hline III, IV, VI, V1, II & 2 \\
\hline Table 6: Cranial Nerve Combinations \\
\hline
\end{tabular}

No patient had involvement of all of the cranial nerves except one patient with leptomeningeal carcinomatosis who presented with bilateral involvement of 7 cranial nerves III, IV, VI, VII, VIII, IX, and X.

\section{DISCUSSION}

Galen was the first to describe the seven pairs of cranial nerves.(3) Willis described the arteries at the base of the brain as well as 10 pairs of cranial nerves. Complete classification of all 12 cranial nerves was done in $18^{\text {th }}$ century.(3) The syndromes of multiple cranial nerve palsies like Jackson (Jackson 1872), Avellis (Avellis 1891), Tapia (Tapia 1905), Collet (Collet 1915), Villaret (Villaret 1916), and Sicard (Sicard 1917) were described toward the end of the 19th century and at the beginning of the 20th century. Unilateral involvement of all 12 cranial nerves is rare; Garcin described progressive involvement of all 12 cranial nerves unilaterally without the rise of intracranial pressure and long-tract signs (Garcin 1927).(3) The syndrome has since been modified to include cases with involvement of 7 cranial nerves ipsilaterally and contralaterally. Hemibase syndrome (Schiffer 1951) describes multiple cranial neuropathy due to skull base lesions. Our study aimed at the aetiological evaluation of multiple cranial neuropathies.

Post-diphtheritic neuropathy was the commonest cause in our series constituting $22.5 \%$ (45 patients) of all the cases. All cases presented with bulbar palsy, 9 cases associated with bilateral VII nerve palsy, 4 cases developed descending paralysis. Out of the 4 patients with descending paralysis, 2 showed demyelinating neuropathy and 2 showed drop in the CMAP amplitudes. The 41 cases who had only bulbar palsy showed normal NCS studies. CSF examination showed evidence of albuminocytologic dissociation.(4)

Bulbar palsy was the most common presentation and first sign of neuropathy. This was in consistence with the study of Piradov MA, Pirogov VN, Popova LM, Avduninall $A^{(5)}$ on 32 patients with severe form of diphtheritic polyneuropathy where bulbar nerve are involved. A fall of immunity in the adult population had resulted in a spectacular return of diphtheria in Eastern European countries such as Latvia since
1993 where it had been successively controlled previously.(6) This can explain some of the adult patients age $>18$ years $(12$ cases, 26\%) affected with the infection.

No patient in our case series developed autonomic disturbances or oculomotor paralysis. But, the study conducted by Inara Logina and Michael Donaghy showed the development of autonomic dysfunction including sinus tachycardia, urinary retention, and hyperhidrosis.(7) Five patients developed myocarditis. of 45 cases, 11 cases came for follow up, out of which 10 patients with bulbar palsy, improved within 4-6 months, 1 case with descending paralysis also improved after I year.

The neuropathology of diphtheria was described by Meyer in 1881. There will be withdrawal of myelin from the paranodes and patchy segmental demyelination confined to the peripheral nervous system.(8) Diphtheritic polyneuropathy and cardiomyopathy are caused by a toxic protein secreted by C. diphtheriae. The toxin is encoded by the tox-bacteriophage gene 18. Only those strains of C. diphtheria harbouring this bacteriophage cause polyneuropathy and cardiomyopathy. The toxin does not cross the blood brain barrier and this explains lack of CNS symptoms.(8)

GBS and MFS were the next most common causes of polycranial neuropathy (32 cases, 16\%) with mean age of presentation was 23.6 years with youngest age of presentation at 15 months.(9) Acute Motor Axonal Neuropathy was the most common presentation in our case series. Seventh, ninth, and tenth cranial nerves were the affected in all these GB syndrome patients. The MFS is seen in two patients who had ataxia, areflexia, and ophthalmoplegia affecting 3, 4, and 6 cranial nerve.(10)

\section{The Polyneuropathy of Diphtheria Mimics GB Syndrome. However, there are few differences. (7)}

1. Diphtheritic polyneuropathy is often biphasic that is motor and sensory deficits in the limbs may become prominent only as the cranial nerve deficits have begun to abate.

2. The preceding history of sore throat in diphtheritic neuropathy.

3. Simultaneous involvement of other organ systems.

4. Recovery of strength and sensation in the limbs is late in diphtheritic polyneuropathy compared to Guillain-Barre syndrome.

In Keane's series, infections were seen in $102(10 \%)$ patients out of which 48 cases were secondary to meningitis. Infections were responsible for MCN in 30 patients $(15 \%)$ of our study. 19 of them were secondary to meningitis. Tuberculous Meningitis was the most common cause of the chronic meningitis affecting the 6th and 3rd cranial nerves more frequently. But, in other studies, the third cranial nerve involvement was more common. Cranial nerve involvement was the most important neurological predictor to differentiate tuberculous from pyogenic meningitis.(11)

Hansen's disease affecting $5^{\text {th }}$ and $7^{\text {th }}$ cranial nerves was consistent with the studies of Bhushan $\mathrm{P}^{(12)}$ and Koyuncu M et al.(13)

Intracranial tumours were responsible for $14 \%$ (28 Cases) of MCN where as in Keane's series tumours were the most common cause of MCN (30\%). Osmania Hospital being a tertiary hospital most of the patients with intracranial 
neoplasms will be referred to the neurosurgery department. This can explain the less number of cases of MCN secondary to neoplasm in our case series. The common tumour was meningioma and location was $\mathrm{CP}$ angle.

Neoplastic processes due to carcinomatous and lymphomatous meningitis are an important cause of multiple cranial neuropathies especially when the patient presents subacutely (Days to weeks). Patients with neoplastic meningitis usually have accompanying headache, meningeal signs, and evidence of increased ICP. Neoplastic meningitis is diagnosed in up to $15 \%$ of patients with systemic carcinomas or haematological malignancies and maybe the first presentation in 5 to $10 \%$ of patients.(14) Small cell lung cancer and myeloblastic leukaemia are more likely to spread to meninges.(15)

Neurolymphomatosis (NL)(16) seen in three of our patients is characterized by infiltration of malignant lymphocytes into the peripheral nervous system particularly the cranial nerves, spinal nerve roots, brachial/lumbar plexus, and/or peripheral nerves. It is a rare neurological manifestation $(0.8-2.5 \%) .{ }^{(16)}$ The most common type of lymphoma responsible for NL is the diffuse large B-cell lymphoma (DLBCL) followed by follicular lymphoma. The exact mechanism of NL development is unclear. Nerve conduction studies demonstrate an asymmetric or focal process that raises the possibility of local invasion of a nerve as seen in NL. This contrasts with the more diffuse pattern of polyradiculopathy seen in leptomeningeal disease and the more symmetric length-dependent polyneuropathy in patients with toxic effects of chemotherapy, both of which occur more frequently than NL.

The cavernous sinus syndrome was studied by Fernandez. $S$ et al. in a series of 12 patients and defined it as involvement of two or more of III, IV, V1 and V2, and VI cranial nerves, or involvement of any one of the above nerves in combination with neuroimaging evidence of cavernous sinus lesion.(17) We found the involvement of third followed by sixth nerve were frequent in cavernous sinus lesion. The other less frequent causes of MCN in our study were osteopetrosis in a six months old child and orbital plate fibrous dysplasia with intraorbital extension. The child with osteopetrosis presented with severe anaemia, hepatosplenomegaly with consecutive involvement of bilateral second and seventh nerves. An adolescent young girl with fibrous dysplasia presented with gradually progressive loss of vision of left eye associated with ophthalmoplegia. Craniofacial fibrous dysplasia is the rare cause of MCN. Till now only a few case reports are present.

\section{CONCLUSION}

The literature on cranial neuropathy of multiple aetiologies is very limited. Keane et al reported 979 cases of MCN in the year 2005. Most of the available literature shows MCN of single aetiology like head trauma, meningitis etc. This is the second largest series of 200 cases of MCN of varied aetiologies. The evaluation of a patient with MCN remains a formidable challenge to the evaluating physician. The differential diagnosis is extensive and the workup can be daunting with expensive and invasive tests. The evaluation requires a systematic yet targeted approach guided by clinical history and examination. Although, many of the causes have specific therapies. The evaluation sometimes leads to a dead end requiring individual clinical discretion to decide on the best possible empiric therapy.

\section{REFERENCES}

1. Beal MF. Multiple cranial nerve palsies: a diagnostic challenge. N Engl J Med 1990;322(7):461-3.

2. Keane JR. Multiple cranial nerve palsies. Arch Neurol 2005;62(11):1714-7.

3. Jain KK in medlink.com/article/multiple cranial neuropathies.

4. Hadfield TL, McEvoy P, Polotsky Y, et al. The pathology of diphtheria. J Infectious diseases 2000;181(Suppl 1):S11620.

5. Piradov MA, Pirogov VN, Popova LM, et al. Diphtheritic clinical analysis of severe forms. Arch Neurology 2001;58:(9):1438-42.

6. Hardy IR, Dittmann S, Sutter RW. Current situation and control strategies for resurgence of diphtheria in newly independent states of the former Soviet Union. Lancet 1996;347(9017):1739-44.

7. Logina I, Donaghy M. Diphtheritic polyneuropathy: a clinical study and comparison with Guillain-barre syndrome. Journal of Neurology, Neurosurgery and psychiatry 1996;67:433-38.

8. Thomas PK, Dyck P. Peripheral neuropathy. $4^{\text {th }}$ ed. ISBN9780721694917, Printbook, release date 2005:2147-50.

9. Akbayram S, Dogan M, Sayin R, et al. Clinical features and prognosis with Guillain-barre syndrome. Annals of Indian Academy of Neurology 2011;14(2):98-102.

10. Sauron B, Bouche P, Cathala HP, et al. Miller fisher syndrome: clinical and electrophysiologic evidence of peripheral origin in 10 cases. Neurology 1984;34(7): 953-6.

11. Moghtaderi A, Alavi-Naini R, Rashki S. Cranial nerve palsy as a factor to differentiate tuberculous meningitis from acute bacterial meningitis. Acta Med Iran 2013;51(2):113-8.

12. Khan A, Sardana K, Koranne RV, et al. Bilateral seventh nerve palsy, a manifestation of polyneuritic leprosy. Indian J of Leprosy 2005;77(2):140-7.

13. Koyuncu M, Celik O, Ozturk A, et al. Audiovestibular system fifth and seventh cranial nerve involvement in leprosy. Indian J of Leprosy 1994;66(4):421-8.

14. Cohen BA. Chronic meningitis. Curr Neurol Neurosci Rep 2005;5(6):429-39.

15. Demopoulos A. Leptomeningeal metastasis. Curr Neurol Neurosci Rep 2004;4(3):196-204.

16. Baehring JM, Damek D, Martin EC, et al. Neurolymphomatosis. Neuro Oncol 2003;5(2):104-15.

17. Fernandez S, Godino O, Martinez-Yelamos $S$, et al. Cavernous sinus syndrome, a series of 126 patients. Medicine (Baltimore) 2007;86(5):278-81. 